\title{
NEW APPROACH OF COSTS OF QUALITY ACCORDING THEIR TREND OF DURING LONG PERIOD IN INDUSTRIAL ENTERPRISES IN SMES
}

\author{
Katarína TEPLICKÁ \\ Technical University of Košice \\ Soňa HURNÁ \\ Mendel University of Brno
}

\begin{abstract}
:
Very important in SMEs is to monitor cost of quality and economic indicators for valuation of cost effectiveness. The main goal of this article is to create classification on cost quality categories in SMEs and to analyze economic quality indicators and their trend during long period. In this article authors use economical and statistical indicators for costs of quality. We use common model PAF, that include prevention costs, evaluation costs, internal failure costs, external failure costs. Total costs, individual simple cost index, cost ratio and cost structure were used. We analyzed data from 50 small enterprises with 10-40 employees with their yearly turnover max 3 mil $€$. The research sample of enterprises was focused on industrial areas of business such as engineering, metallurgy, automotive industry. We analyzed the quality costs in SMEs by the average value of quality cost in all surveyed enterprises. Results of this research brought labeling of cost of quality in SMEs by model the PAF for 10 categories for various enterprises, what is very important for comparing of results of QMS in SMEs. Based on the reference indicators of the total costs of quality in SMEs we can conclude their drop. Reducing the costs of quality was reflected in particular in reducing the costs of internal and external errors. In assessing the economic efficiency in SMEs plays an important role the overall cost that were increasing in reporting period. Very important result is that the cost of quality did not influenced overall cost. This fact is positive for competitiveness in SMEs because it shows a quality of production and product. Reducing of cost of quality brought improving of product quality; reduced customer's complaints brought financial savings. The economic efficiency indicator shows a value above e $>1$. It means that, despite rising cost enterprises generate revenues that are significantly higher than the input factors of production. Cost effectiveness helps to improve TQM performance.
\end{abstract}

Key words: cost, efficiency, indicators, profit, quality

\section{INTRODUCTION}

Economics of quality is one important part of QMS and very important instrument for evaluation. Cost of quality pursuing activities related to quality such as prevention, evaluation, quality measurement and detection of poor quality create base of quality [19]. Economic optimum of quality is to find a balance between quality and costs of quality. It is very important to monitor quality costs and their synergistic effect to economic efficiency. The main goal of this article is to create classification of categories of costs of quality in SMEs and to analyze economic indicators for quality and their trend during long period. With this research, we want to determine the impact of costs of quality in SMEs on the overall cost of the business and their influence on profit generation. The most commonly is used classification as a model PAF. This model has three cost groups - prevention, appraisal and failure costs [23]. This model is used in various industry areas and in services industries [21]. Evaluation of the quality costs and use of statistical quality indicators allows us to monitor the dynamics of quality costs and percentage of the total costs [13]. Authors in various articles are generally considered that traditional cost accounting methods do not provide accurate cost data for the measurement of quality cost [6]. In praxis is very important to evidence quality costs through PAF model or other models. Performance measurement is a fundamental principle of business management and it consists too of quality indicators [18]. Enterprises make an effort to meet their customer's requirements related to the products. Satisfied customers can help to generate profit and profit is an important factor for development of enterprises. This can be achieved by quality management in the product creation phase. In this phase can be decrease cost of quality in SMEs [10]. 


\section{LITERATURE REVIEW}

Integrating two areas for a sustainable business performance is connected on a quality management system and defining a competency-based model related to measurement and evaluation of performance. A key performance indicator is the important element in every quality management system within a business [24]. One of key indicator of QMS is cost effectiveness that is presented in this article. Alglawe \& col. (2019) have suggested for COQ model new dynamics approach. This approach is based on the traditional prevention-appraisal-failure (PAF) concept. The data were collected from real automobile manufacturing for valuation of the customer satisfaction. Results of survey reveal that when quality costs are considered in the COQ model, the number of new customers and production units in decreases [1]. Quality management system is one of the key business indicators in industry on Slovakia. In praxis is important to use adequate quality management. This article addresses categories of costs of quality by PAF model. Quality is a key competitive factor in globalized market. Quality costs must to create effective quality management system [8, 23]. Schiffaerova and Thomas (2006) presented in their article that companies which do adopt $\mathrm{COQ}$ method are successful in reducing quality costs and improving quality of product. COQ model must suit the specific situation, environment, purpose and needs of the enterprises in order to have a chance to become a successful systematic tool in a quality management system. The survey shows that the method most commonly implemented is the classical model PAF prevention-appraisal-failure model that we used in this article [14]. Cost classification by the PAF model is not correct for various industry area for example in supply chain because it creates risks of availability of partial information. For the supply chain is used mostly Monte Carlo simulation method as a preferable [2]. Muhammad R. (2019) et al. have created model that it describes the dynamics of the quality costs and economic benefits of quality improvement. This mathematical model measures the quality cost and economic benefits of manufacturing companies. The economic benefits are obtained from saving quality costs resulting from achieving operational performance targets. Results of model shows to: If the value of the model parameters increases, then the economic benefits will increase as well, and give a shorter return period of investment. And vice versa, if the value of the model parameters decreases, then the economic benefits will decrease as well and give a longer return period of investment [11]. Cost effectiveness is very important indicator of QMS in SMEs and it is connected with cost categories. This indicator is using in various area. Cremieux et al. (1999) presented its using in treatment. To measure the cost effectiveness in treatment is very hard but it is very important to compare results of treatment that brings cost effective model and support quality of life and improve health status. It is significance instrument for QMS system [5]. Improvement of data processing and information flow relating to product quality means better decision making on product quality, reduction of defects and reducing of costs. Based on the accurate and timely received information on product quality, needed interventions to the process can be realized to reduce the defects and reducing of cost [17]. In QMS is very important to analyse risks as an instrument how to decrease costs of quality. Markulik et al. (2016) introduced that the risk assessment is a basic tool of every management system (at this time very important for quality management system). It enables appropriate decision making. Being prepared to manage risks involves the ability to identify them, assess them and take appropriate measures [9]. Current trends of Quality Management systems are oriented on looking for the solutions, which prevent the losses by effective and efficient tools. Integrated approach to the risk management in the man-machine-environment system is oriented towards allcomponentsofthis system. Generic Risk Assessment Model (GRAM) is defined conditions for the risk management of the individual system parts. The aim of GRAM is to give management the necessary information for their decision making processes $[12,20]$. The reducing of cost of quality is connected with innovations. The innovation for QMS means an intelligent approach towards organisational change that it regarding organisational culture too. Implementation of new approach webbased Management System Role-Play Simulation (MSRPSÂ) reflects the changes in structure, in terminology of the ISO management system standards and helps people to adapt quickly [25]. The successful of quality management system is measured by financial and also non-financial indicators. In this article we analyze the economic-statistical quality indicators using a breakdown of the costs of quality according to the PAF model. Implementation of quality cost control is very important instrument for improving in area of quality management and quality cost [4]. This approach creates framework for measuring and evaluating quality costs [22]. Bamford and Land (2006) presented measurement instrument for costs of quality for business improvement in an industry company with direction on Footwear Company. This new instrument is calculation of quality costs. Quality costing can only be used as a management tool if the data presented is both accurate and valid. Effective measurement of quality costs improves business performance [3, 7]. Soundararajan and Reddy (2019) presents cost reduction and quality improvement in SMEs by implementing DMAIC instrument. Results of this application DMAIC in SMEs recorded price reduction and increasing of quality [15]. Sturm, Keiser, Hartmann (2019) present that quality costs depend on performance in manufacturing in the long-run. The authors then examine whether it is possible to reduce internal and external failure cost over time without increasing prevention and appraisal expenditures in return (model PAF). Authors obtained connections between total cost of quality, its components and overall quality performance [16]. Most authors who analyze the costs of quality in small and medium-sized enterprises use the PAF model to categorize costs, because this model is in this time the best for SMEs in terms of classification. Today is known 
also the $A B C$ approach, which is based on a process approach, is gaining prominence. In the sense of $A B C$ model are costs classified as value-added and non-value-added costs. Due to the fact that this approach requires significant changes in the record of quality costs, it is used mainly by large companies. Surveys show only a basic breakdown of the PAF model, and in depth no one has yet paid attention to individual cost items in the field of mechanical engineering in SMEs. Surveys on the classification of quality costs in small and medium-sized enterprises are not presented in the scientific field significantly, as research aimed at unifying quality costs in SMEs have not been carried out. In the most exist scientific papers, the authors present specific tools for reducing the cost of quality, e.g. Lean production, 5S, Kaizen and others.

\section{RESEARCH METHODOLOGY}

Monitoring of the quality costs can be made on the basis of different approaches. Authors considers that for the evaluation of economic and statistical indicators of quality and their classification is model PAF one of the best. Model PAF was created by the American company General Electric and is part of the British standard BS 6143, which divides the costs of quality to the category of the costs of prevention, assessment costs, costs of errors [6, 22]. These costs groups include:

Prevention costs - (efforts to avoid disagreement) the costs of any activity relating to the investigation, prevention, or reducing the risk of error, as well as the costs of quality improvement based corrections. This includes also the costs of various quality analysis, planning, information systems, upbringing, motivation and education, etc.

Appraisal costs - (assessment of the quality status) the costs for valuation whether the defined quality requirements have been reached. This includes all costs for measuring, checking, testing and verification of products and processes.

Internal failure costs - (internal failure) the costs incurred within the company due to handling of errors in fulfilling quality requirements of the customer. Include all costs of removal of disagreements with the documentation, on overtime for repairing, re-inspections and so on.

External failure costs - (external failure) the costs arising outside the company after delivery to the customer (user), arising from failure to meet user requirements on quality. They arise during use of the product as a result of poor quality of supplier's work [6, 22].

For evaluation of economic and statistical indicators we will use exactly this approach in the assessment of quality costs, because the following indicators are based precisely on the model of the PAF. To determine the total costs relating to the quality at the producer by formula (1). (Nov) we base on the breakdown of costs according to the PAF model as follows:

$$
N_{Q V}=N_{I}+N_{E}+N_{H}+N_{P}
$$

where:

$N_{1}$ - total cost of internal errors for the period,

$N_{E}$ - total cost of external errors for the period, $N_{H}$ - total cost of evaluation for the period,
$N_{\mathrm{p}}$ - total cost of prevention for the period.

The second statistical indicator which reflects the development of costs the observed period we refer to as Individual simple cost index related to the quality at manufacturer by formula $(2)$. $\left(I_{N Q}\right)$ is used to monitor the dynamics of quality costs in two consecutive periods and expressed as follows:

$$
I_{N Q}=\frac{N_{Q 1}}{N_{Q 0}}
$$

where:

$N_{Q 1}$ - the total amount of costs related to the quality at manufacturer in the current period (1).

$N_{Q 0}$ - the total amount of costs related to the quality in the base period (0), immediately preceding period.

In assessing the economic efficiency of the company plays an important role the overall corporate costs, resulting from the exploitation of production factors, which take a part in making the profit. Indicator which expresses the relationship between the costs of quality and total costs is specified as the costs structure by formula (3) resp. portion of quality related costs to the total costs of the manufacturer $\left(\mathrm{S}_{\mathrm{NQ}}\right)$. Its use is effective if we want to regularly monitor the percentage of quality costs devolving to the processes of planning, regulating and improving quality in relation to total expenses.

$$
S_{N Q}=\frac{N_{Q V}}{N_{c}} \cdot 100 \%
$$

where:

$N_{Q v}$ - total quality cost,

$N_{c}$ - total cost.

We monitor costs of quality in the monitored period to the total costs of the enterprise as operational, financial and extraordinary expenses. Formula (4) defines the percentage of the internal and external errors costs to the total quality costs and thus highlights the extent of deficiencies in quality management.

$$
\text { Snch }=\frac{N i+N e}{N Q v} \cdot 100 \%
$$

An important indicator for assessing economic efficiency in terms of quality is also an index of costs, which reflects how much money units of costs fall to one unit of income. This index can be expressed relative as a percentage by formula (5). Costs ratio is expressed by the following equation:

$$
n=\frac{N_{Q V}}{T} \cdot 100 \%
$$

where:

$N_{Q v}$ - total quality cost,

$T$ - revenues.

Efficiency (formula 6) is the ability to avoid wasting materials, energy, efforts, money, and time in doing something or in producing a desired result. In more mathematical or scientific terms, it is a measure of the extent to which input is well used for an intended task or function (output).

$$
e=T / N c
$$

where:

$T$ - revenues,

$N_{c}$ - total cost.

As the authors state, it is possible to use the $A B C$ model in enterprises in specific cases, but its introduction into SMEs would be financially demanding. Therefore, this 
model is mostly implemented in large companies. The research was implicated in small and medium-sized enterprises. At the same time, the risk of applying this $A B C$ model is an administrative and a change in the system of tracking cost items within processes what it means problem for SMEs.

\section{RESULTS OF RESEARCH}

In this article we presented economic - statistical analysis orientated on quality indicators in SMEs whose business is manufacture metal castings, wood products manufacturing, service, rental, storage activity, metal finishing, production of component for automotive, production of mechanic component, welding, production of engineering component for machines and equipment. We analyzed data from 50 small enterprises with 10-40 employees and their yearly turnover was to $\max 3 \mathrm{mil}$. $€$. The research sample of enterprises was focused on industrial areas of business such as engineering, metallurgy, automotive industry. The sample of enterprises is not a random sample, but a targeted sample of enterprises. Engineering enterprises were selected on the basis of established criteria according to the number of employees and turnover in the enterprises. We obtained all information regarding quality costs from company databases, from double-entry accounting and from internal enterprises records. The selection of all enterprises was focused on enterprises that have a quality management system in place and keep records of quality costs. The acquisition of quality cost data limited the sample of enterprises to enterprises that have a quality management system in place. Therefore, the research sample was targeted so that we could specify general conclusions for small and medium-sized enterprises in the engineering industry in SMEs. We obtained all information of enterprises by personal visit and interview in selected enterprises. Data collection also took place through students who participated of the research project solution. Reliability of information about costs of enterprises is high, because all information belong in to accounting that are manage by Slovakian law No 431/2002 and by standard EN ISO 9001:2016. Authors analyzed the quality costs in SMEs by the average value of quality cost of all enterprises. We categorized individual types of costs of quality by PAF model. Model PAF classified quality cost in four categories - Prevention costs, Evaluation costs, internal errors cost, external errors cost. In this article we compared values of cost of quality and economic indicators during 9 years and we obtained very important information for cost classification in SMEs. Enterprises documented different names of costs of quality, so we adjusted them according to the PAF model. For the comparation was created new one model for general label of costs of quality in SMEs. An overview of individual types of quality costs is presented in Table 1.
Table 1

Labeling of cost of quality by model PAF

\begin{tabular}{|c|c|c|c|}
\hline $\begin{array}{l}\text { Prevention } \\
\text { costs }\end{array}$ & Appraisal costs & $\begin{array}{l}\text { Internal failure } \\
\text { costs }\end{array}$ & $\begin{array}{c}\text { External } \\
\text { failure costs }\end{array}$ \\
\hline $\begin{array}{l}\text { Cost of } \\
\text { trainings } \\
\text { for QMS }\end{array}$ & $\begin{array}{l}\text { Cost of produc- } \\
\text { tion control }\end{array}$ & Cost of scrap & $\begin{array}{l}\text { Cost } \\
\text { of complaints }\end{array}$ \\
\hline $\begin{array}{l}\text { QM depart- } \\
\text { ment } \\
\text { trainings } \\
\text { Workers- } \\
\text { welders } \\
\text { trainings }\end{array}$ & $\begin{array}{l}\text { Cost of initial } \\
\text { control } \\
\text { Cost } \\
\text { of production } \\
\text { control } \\
\text { Cost } \\
\text { of maintenance }\end{array}$ & $\begin{array}{l}\text { Cost } \\
\text { of individual } \\
\text { products } \\
\text { wasters }\end{array}$ & $\begin{array}{l}\text { Fines cost } \\
\text { Claims cost } \\
\text { Cost } \\
\text { of penalties }\end{array}$ \\
\hline $\begin{array}{l}\text { Cost } \\
\text { of investment } \\
\text { in QMS }\end{array}$ & Cost of Testing & Cost of failures & Cost of looses \\
\hline $\begin{array}{l}\text { Cost to assess } \\
\text { supplier } \\
\text { Cost of docu- } \\
\text { mentation }\end{array}$ & $\begin{array}{l}\text { Cost } \\
\text { of metrology } \\
\text { Cost } \\
\text { of calibration }\end{array}$ & $\begin{array}{l}\text { Mechanical } \\
\text { machines } \\
\text { errors } \\
\text { Material }\end{array}$ & $\begin{array}{l}\text { Cost } \\
\text { associated } \\
\text { with the loss } \\
\text { of key }\end{array}$ \\
\hline $\begin{array}{l}\text { Cost } \\
\text { of documen- } \\
\text { tation }\end{array}$ & $\begin{array}{l}\text { Cost } \\
\text { of defectoscopy } \\
\text { Cost of test } \\
\text { tools } \\
\text { Cost of quality } \\
\text { audits } \\
\text { Audit costs }\end{array}$ & $\begin{array}{l}\text { forming errors } \\
\text { Material errors } \\
\text { Welding errors } \\
\text { Surface } \\
\text { treatment } \\
\text { errors }\end{array}$ & $\begin{array}{l}\text { customer } \\
\text { Cost of } \\
\text { caused by } \\
\text { production } \\
\text { delays } \\
\text { Cost } \\
\text { of stopping } \\
\text { production }\end{array}$ \\
\hline
\end{tabular}

Source: Own source according Internal sources of the SMEs enterprises [22].

We have harmonized by this approach label of quality cost for SMEs, which is very important in terms of monitoring, evaluating quality costs and their comparing. The confusion in different types of cost of quality can affect the decision-making process in the implementation of corrective measures in SMEs. We have created cost category labels because enterprises use different names for various cost types. For example for category: cost of complaints use names as an: claims cost, cost of complaints in warranty, cost of complaints out of warranty, cost of objection, product service, product liability, product recall, cost of penalties, fines cost. Cost of losses contains that cost: loss of reputation, cost associated with the loss of key customer, cost of loss caused by production delays, cost of stopping production and other. Cost of testing contains that cost: cost of metrology, cost of calibration, cost of defectoscopy, cost of inspection of equipment, cost of test tools. A system of quality cost labeling in SMEs is necessary for comparative analysis and evaluation of the effectiveness of the quality management system in SMEs. Labeling of cost of quality in SMEs is basic benefit of this research and this labeling of cost of quality by model PAF is instrument for various enterprises in SMEs. We achieved connection of all type of cost of quality and we created ten category cost.

We analyzed the quality costs in SMEs by the average value of quality cost in all enterprises. Results of cost of quality are presented in Table 2 . 
Table 2

Average cost of quality by model PAF - comparing

\begin{tabular}{lccc}
\hline \multicolumn{1}{c}{$\begin{array}{c}\text { Model PAF/Cost } \\
\text { of quality }(\boldsymbol{\epsilon})\end{array}$} & $\mathbf{2 0 1 7}$ & $\mathbf{2 0 1 8}$ & $\mathbf{2 0 1 9}$ \\
\hline Prevention cost & 18090 & 13350 & 11560 \\
Evaluation cost & 120500 & 115850 & 117350 \\
Internal errors cost & 8402 & 5432 & 3450 \\
External errors cost & 51711 & 31500 & 22200 \\
$\quad$ Cost of quality $(\boldsymbol{\epsilon})$ & $\mathbf{2 0 1 1}$ & $\mathbf{2 0 1 2}$ & $\mathbf{2 0 1 3}$ \\
Prevention cost & 19085 & 14278 & 13829 \\
Evaluation cost & 117110 & 116790 & 116480 \\
Internal errors cost & 9402 & 7432 & 1450 \\
External errors cost & 61711 & 31478 & 24186 \\
\hline
\end{tabular}

Source: Internal sources of the SMEs enterprises [22].

The highest value of quality costs is the evaluation cost over the reporting period. External failure costs, internal failure costs and prevention costs have been step by step reduced. In the classification of quality costs we can conclude that the highest value - the costs of evaluation is related to the production process that is necessary for the quality control of products such as: measurement, calibration, input and output monitoring, sampling. The value of the quality costs in SMEs is high and cannot be significantly reduced because otherwise it could be expected that there will be a decrease in product quality and increase of the costs of errors. Detailed examination of these groups of quality costs we implemented through economic-statistical indicators followed.

Economic-statistical indicators we analyzed by formulas 1 , $2,3,4,5,6$. Indicators as efficiency, structure of cost, cost ratio, profit are very important financial indicators that influence financial situation of SMEs. Small businesses are the backbone of the economy, a key source of job opportunities and a breeding ground for business ideas. Results of economic-statistical analysis are presented in Table 3.

Table 3 Individual simplex cost index in SMEs

\begin{tabular}{cccc}
\hline$I_{\text {NQ }}$ & $I_{\text {NQ }}$ & $I_{\text {NQ }}$ & $I_{\text {NQ }}$ \\
$\mathbf{2 0 1 2 / 2 0 1 1}$ & $\mathbf{2 0 1 3 / 2 0 1 2}$ & $\mathbf{2 0 1 8 / 2 0 1 7}$ & $\mathbf{2 0 1 9 / 2 0 1 8}$ \\
\hline 0.75 & 0.97 & 0.74 & 0.87 \\
0.99 & 0.99 & 0.96 & 1.01 \\
0.79 & 0.19 & 0.65 & 0.64 \\
0.51 & 0.77 & 0.61 & 0.70 \\
\hline
\end{tabular}

Source: Own source according internal sources of the SMEs.

Cost index shows the change in the costs of quality in the two reporting periods. Overall, the development of quality costs recorded a decline, as the index values were below value 1, except for developments in 2018-2019, when evaluation costs increased. Overall, we can observe a reduction in the cost of quality, which is a positive trend, because quality costs are part of the total cost that affects profit generation in SMEs. As part of the economic analysis, we monitored the cost of quality, total cost, profit, revenue, cost structure, efficiency. All these economic indicators are factors that influence the performance of enterprises and their competitiveness in the market (Table 4).
Table 4

Economic indicators of cost of quality by model PAF

\begin{tabular}{lccc}
\hline \multicolumn{1}{c}{ Cost of quality } & $\mathbf{2 0 1 7}$ & $\mathbf{2 0 1 8}$ & $\mathbf{2 0 1 9}$ \\
\hline $\mathrm{N}_{\mathrm{i}}+\mathrm{N}_{\mathrm{e}}$ & 60113 & 36932 & 25650 \\
$\mathrm{~N}_{\mathrm{QV}}$ & 198703 & 166132 & 154560 \\
$\mathrm{Nc}$ & 129562925 & 130721315 & 13875835 \\
$\mathrm{~S}_{\mathrm{NQ}}$ & $\mathbf{0 . 1 5 \%}$ & $\mathbf{0 . 1 2 \%}$ & $\mathbf{0 . 1 1 \%}$ \\
$\mathrm{S} \mathrm{nch}$ & $\mathbf{3 0 . 2 \%}$ & $\mathbf{2 2 . 2 \%}$ & $\mathbf{1 6 . 6 \%}$ \\
$\mathrm{T}-$ revenues & 156362506 & 172821315 & 183858216 \\
$\mathrm{n}-$ cost ratio & $\mathbf{0 . 1 2}$ & $\mathbf{0 . 0 0 0 9}$ & $\mathbf{0 . 0 0 0 8}$ \\
$\mathrm{Z}-$ profit & $\mathbf{2 6 7 9 9 5 8 1}$ & $\mathbf{4 2 1 0 0 0 0 0}$ & $\mathbf{4 5 0 9 9 5 8 1}$ \\
$\mathrm{e}-$ efficiency & $\mathbf{1 . 2}$ & $\mathbf{1 . 3 2}$ & $\mathbf{1 . 3 3}$ \\
\multicolumn{1}{c}{ Cost of quality } & $\mathbf{2 0 1 1}$ & $\mathbf{2 0 1 2}$ & $\mathbf{2 0 1 3}$ \\
$\mathrm{N}_{\mathrm{i}}+\mathrm{N}_{\mathrm{e}}$ & 71113 & 38910 & 25636 \\
$\mathrm{~N}$ Qv & 207298 & 169978 & 155945 \\
$\mathrm{Nc}$ & 119262925 & 125621734 & 128758635 \\
$\mathrm{~S}$ & $\mathbf{0 . 1 7 \%}$ & $\mathbf{0 . 1 3 \%}$ & $\mathbf{0 . 1 2 \%}$ \\
$\mathrm{S} \mathrm{nch}$ & $\mathbf{3 4 . 3 \%}$ & $\mathbf{2 2 . 9 \%}$ & $\mathbf{1 6 . 5 \%}$ \\
$\mathrm{T}-$ revenues & 129362706 & 130721315 & 131758216 \\
$\mathrm{n}-$ cost ratio & 0.16 & 0.13 & 0.12 \\
$\mathrm{Z}-$ profit & 10099781 & 5099581 & 2999581 \\
$\mathrm{e}-$ efficiency & $\mathbf{1 . 0 8}$ & $\mathbf{1 . 0 4}$ & $\mathbf{1 . 0 2}$ \\
\hline
\end{tabular}

Source: Own source according internal sources of the SMEs [22].

We followed the development of indicators from 2011 to 2019. We found out what changes have occurred after a long period of business in SMEs and how changed cost of quality.

\section{DISCUSSION}

Based on the reference indicators of the total costs of quality in SMEs we can conclude their drop. Reducing the costs of quality was reflected in particular in reducing the costs of internal and external errors. Savings were recorded in prevention cost and evaluation cost. The PAF model recommends costs reductions in the internal and external errors that presented Rodin and col. (2012) in their article. Costs of prevention in regard of continuous quality improvement may not reduce, but rather may record an increase, because prevention is considered to be an instrument of the prevention of errors and deficiencies, non-conformities in quality that presented Bamford and col. (2006) in their article. Significant change of the cost of quality was recorded in 2019. Evaluation costs first was decreased and then increased. The value of those cost include cost on metrology, calibration and defectoscopy that create in each reporting period. In assessing the economic efficiency in SMEs plays an important role the overall cost that were increasing in reporting period. Those overall cost influence to using of production factors, which take a part by create of the profit. Indicator which expresses the relationship between the costs of quality and total costs is specified as the costs structure. Structure of cost of quality was decreasing from $0.15 \%$ to $0.11 \%$. Soundararajan and Reddy (2019) presented reduction of cost of quality by DMAIC model in SMEs and say that for quality improvement is important level of cost of quality at level $20 \%$. Cost of quality in SMEs are from $0.11 \%$ to $0.15 \%$ in year $2017-2019$ and structure in year $2011-2013$ is very small from $0.12 \%$ to $0.17 \%$, because in this period the quality management system was not implemented in enterprises as it is today. Cost structure is 
important indicator and its use is effective if we want to regularly monitor the percentage of costs of quality in various processes in relation to total cost of the SMEs. The costs structure is an important indicator in terms costs optimization and an instrument for exploring the possibilities of reducing the unproductive cost items (Figure 1). Cost structure during period from 2011 to 2019 is very positive, because cost of quality creates low value of total cost in enterprises in SMEs.

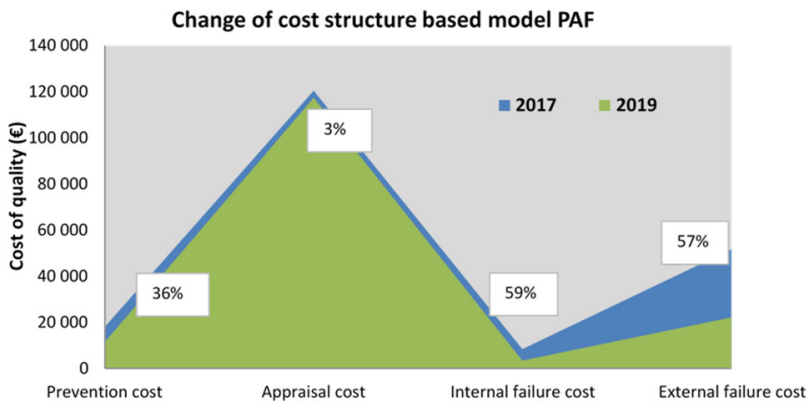

Fig. 1 Change of cost of quality structure by model PAF 2017-

\section{9}

Source: Own source according internal sources of the SMEs.

Cost of quality in relation to creation of profit participate low percentage it means cost of quality does not important influence to profit. Revenues in SMEs increased during the reporting period. Total costs also increased proportionally. The increase in costs and revenues recorded an increase in profit. In year 2011-2013 the profit was decreased, and the cost and revenues were increased step by step. The economic efficiency indicator shows a value above e $>1$. It means that, despite rising cost enterprises generate revenues that are significantly higher than the input factors of production. This positive development in SMEs points to an effective quality management system, which is also reflected in the value of quality costs that have fallen. The cost indicator is very low, which means that the cost of quality is low in 1 euro, which is a positive trend. This indicator ranges from 0.0008 euro to 0.16 euro on 1 euro of revenue. The results of the economic analysis point to low quality costs in SMEs, which means that these quality costs do not affect profit generation. Businesses reduce quality costs despite rising overall costs. Businesses achieve efficiency above 1, which means they generate revenue higher than costs and thus generate profits, which is a great competitive advantage for the business environment.

\section{CONCLUSION}

Total quality management is a major business strategy for all enterprises in various areas of business in SMEs. All described indicators in this article are important for improving TQM performance. In the evaluation of quality costs also other methods can be used in practice that directly detects relationships between the cost of quality and total cost. These methods include regression and correlation analysis, time series analysis, analysis of deviations, Pareto analysis, but also statistical testing through Grubs test, $\mathrm{F}$ test. In terms of achieving high level of economic efficiency, it is necessary to determine level of costs of quality, which can ultimately positively or negatively influence the profit in SMEs. Results of this research brought for SMEs labeling of cost of quality in SMEs by model PAF for various enterprises. Based on the reference indicators of the total costs of quality in SMEs we can conclude their drop. Reducing the costs of quality was reflected in particular in reducing the costs of internal and external errors. Reducing of internal and external errors cost brought improved product quality, reduced customer's complaints, brought financial savings. An important indicator for assessing economic efficiency in terms of quality is an index of costs that was reduced. Savings were recorded in prevention cost and evaluation cost. In assessing the economic efficiency in SMEs plays an important role the overall cost that were increasing in reporting period. The economic efficiency indicator shows a value above e $>1$. It means that, despite rising cost enterprises generate revenues that are significantly higher than the input factors of production. In conclusion we can state that the balance between production quality and cost of quality is an indicator that expresses mutual synergy. For enterprises in SMEs is very important record and evaluate of cost of quality which in the context of business costs should not exceed level $20 \%$. The cost of quality in selected enterprises in SMEs are moving in recommended level to $20 \%$, which can also be seen in Table 4. That is, SMEs apply in the principles of continuous improvement in the quality management system and reducing quality costs. For SMEs create cost economic and financial indicators those SMEs enterprises to spend to ensure the quality of their products, processes and services. Based on the economic-statistical analysis the enterprises can control and influence the level of costs on quality and eliminate their share in the total costs.

\section{ACKNOWLEDGEMENT}

This contribution is part of project KEGA 049TUKE-4/2019 and VEGA 1/0651/2018.

\section{REFERENCES}

[1] A. Alglawe, A. Schiffauerova, O. Kuzgunkaya. "Analysing the cost of quality within a supply chain using system dynamics approach." Total quality management and Business Excellence, vol.30, no. 15-16, pp. 1630-1653, 2019.

[2] A.K. Pattanayak, A. Prakash, R.P. Mohanty. "Risk analysis of estimates for cost of quality in supply chain: a case study." Production Planning \& Control, vol. 30, no 4, pp. 299-314, 2019.

[3] D. Bamford, N. Land. "The application and use of the PAF quality costing model within a footwear company." International journal of quality and reliability management, vol. 23, no.3, pp. 265-271, 2006.

[4] R. Colin, B. Falk, M. Durlich, R. Jochem. "Do quality costs still matter?" Total quality management \& business excellence, vol. 26, no. 7-8, pp. 1-12, 2015.

[5] P. Cremieux, S.N. Finkelstein, E.R. Berndt et al. "Cost effectiveness, Quality - Adjusted Life-years and supportive care." Pharmacoeconomics, no.16, pp. 459-472, 1999.

[6] J. Hrubec, E. Virčíková, a kol. Integrovaný manažérsky systém. SPU: Nitra, 2009. 
[7] S. Hurná, K. Teplická, M. Straka. “Use of statistical quantitative methods for monitoring quality parameters of raw materials." Przemysl chemiczny, vol. 97, no. 1, pp. 59-63, 2018.

[8] CH.Y. Ching. "Improving the definition and quantification of quality costs." Total quality management \& business excellence, vol. 19, no. 3, pp. 175-191, 2008.

[9] Š. Markulik, et al. "Causal dependence of events under management system conditions." MM Science Journal, vol. 10, pp. 1040-1042, 2016.

[10] Š. Markulik, R. Kozel. "Transformation of product characteristics in terms of a management system." MM Science Journal. vol. 20, pp. 900-902, 2016.

[11] M. Rosiawan, M. L. Singgih, E. Widodo. "Model of quality costs and economic benefits of a business process of manufacturing companies." Cogent Engineering, vol 6, no 1, pp. 125-132, 2019.

[12] H. Pačaiová, J. Sinay, A. Nagyová. “Development of GRAM - A risk measurement tool using risk based thinking principles." Measurement, vol. 100, pp. 288-296, 2017.

[13] F. Sgardea, M. Stanila, O. Georgiana, M.C. Partal. "Total quality cost - a reconsideration of the importance-performance analysis in managerial accounting." Metalurgia, vol. 15, pp. 49-52, 2009.

[14] A. Schiffauerova, V. Thomson. "A review of research on cost of quality models and best practices", International Journal of Quality \& Reliability Management, vol. 23 no. 6, pp. 647-669, 2006.

[15] K. Soundararajan, K.J. Reddy. "Cost reduction and quality improvement using DMAIC in the SMEs." Internationl journal of productivity and performance management, vol. 68, no 8, pp. 1-15, 2019.

[16] S. Sturm, G. Keiser, E. Hartmann. "Long run dynamic between cost of quality and quality performance." International journal of quality and reliability management, vol. 36, no. 8, pp. 78-86, 2019.

[17] A. Sütőová, S. Segiňáková. “Improving information flow for decision making on product quality in the automotive industry." Quality Innovation Prosperity, vol. 22, no 1, pp. 71-78, 2018.

\author{
Katarína Teplická \\ ORCID ID: 0000-0002-4827-6781 \\ Technical University of Košice \\ Institute of Earth Sources \\ Park Komenského 19, Košice, Slovak Republic \\ email: katarina.teplicka@tuke.sk
}

\section{Soňa Hurná}

ORCID ID: 0000-0001-7001-4860

Mendel University of Brno

Faculty of Business and Economics

Zemědelská 1, Brno, Czech Republic

email: sona.hurna@mendelu.cz
[18] A. Sütőová, M. Šolc. "Utilization of statistical methods within the European Performance satisfaction index rating methodology." Quality, Innovation, Prosperity, vol. 13, no 1, pp. 77-83, 2009.

[19] A. Šatanová, J. Závadský, M. Sedliačiková, M. Potkány, Z. Závadská, M. Holíková. "How Slovak small and medium manufacturing enterprises maintain quality costs: an empirical study and proposal for a suitable model." Total Quality management and Business Excellence, vol. 25, no 6, pp. 146-154, 2014.

[20] E. Škvareková, et al. "Analysis of Risk Factors for Underground Coal Gasification." Management Systems in Production Engineering, vol. 27, no 4, pp. 227-235, 2019.

[21] F. Talib, Z. Rahman, M.N. Quereshi. "Prioritizing the practices of total quality management: An analytic hierarchy process analysis for the service industries." Total Quality Management, vol. 22, no. 12, pp. 1331-1351, 2011.

[22] K. Teplická, M. Pavlíčková. "Economic indicators of quality of quality and theri influence on cost effectiveness, " in Proceedings of the scientific conference quality and leading innovation" Hradec Králové, Czech Republic 2014, pp. 105116.

[23] K. Teplická, S. Hurná, J. Kádárová. “Comparison of Using Managerial Instruments in Industry Companies in Slovakia and the Czech Republic." Technology, Education, Management, Informatics, vol. 8, no. 4, pp. 1191-1197, 2019.

[24] J. Závadský, et al. "Competences in the quality management system evaluation based on the most worldwide used key performance indicators." Quality - Access to Success, vol. 20, no 169, pp. 29-41, 2019.

[25] K. Zgodavová, M. Kisela, A. Sütőová. “Intelligent approaches for an organisation's management system change." TQM Journal, vol. 28, no. 5, pp. 760-773, 2016. 